\title{
O CURRÍCULO DE FORMAÇÃO EM EDUCAÇÃO FÍSICA: ANÁLISE DAS PRODUÇÕES CIENTÍFICAS
}

\author{
THE PHYSICAL EDUCATION CURRICULUM: ANALYSIS OF SCIENTIFIC WORKS
}

\author{
EL CURRÍCULO DE FORMACIÓN EN EDUCACIÓN FISICA: ANÁLISIS DE LAS \\ PRODUCCIONES CIENTIIFICAS
}

\author{
Moisés Sipriano Resende*, Ari Lazzarotti Filho*
}

\begin{abstract}
Palavras chave:
Currículo.

Formação

profissional.

Educação Física.

Pesquisa.

Resumo: A pesquisa teve como objetivo investigar como as produções científicas veiculadas por periódicos no período de 2000 a 2017 têm analisado o currículo de formação em Educação Física. Foi realizada uma pesquisa do tipo bibliográfica em dez periódicos classificados no Qualis Capes de A1 a B3 em Educação Física e analisados o título, o resumo e as palavras-chave de 230 artigos. Para a análise dos dados foi empregada a análise de conteúdo. O nível de desenvolvimento curricular mais analisado foi o currículo realizado, caracterizado por conhecimentos aprendidos pelos estudantes. Nenhuma pesquisa analisou o currículo avaliado. O tema mais investigado foi "Disciplinas dos cursos", e a maioria das pesquisas não utiliza referências para conceituar currículo. Sugere-se maior articulação entre os níveis do currículo com ênfase no currículo avaliado.
\end{abstract}

Keywords: Curriculum. Professional Training. Physical Education and Training. Research.

Palabras clave: Currículo. Capacitación Profesional. Educación Física. Investigación.
Abstract: This study investigated how scientific works published in 2000-2017 analyzed the curriculum for training Physical Education teachers. Bibliographic research was carried out in ten Physical Education journals classified as A1-B3 by Qualis Capes. Titles, abstracts and keywords of 230 articles were submitted to content analysis. The most widely analyzed curriculum development level was the so-called "realized curriculum", i.e. knowledge learned by students, while the so-called "evaluated curriculum" was not analyzed. The most widely investigated topic was course subjects and most of the research does not use any reference to conceptualize curriculum. Better coordination between curriculum levels is suggested, with emphasis on the evaluated curriculum.

Resumen: Este trabajo tuvo como objetivo investigar cómo las producciones científicas divulgadas por periódicos en el período de 2000 a 2017 han analizado el currículo de formación en Educación Física. Se realizó una investigación de tipo bibliográfica en diez periódicos clasificados en el Qualis Capes de A1 a B3 en Educación Física y fueron analizados el título, el resumen y palabras clave de 230 artículos. Para el análisis de los datos se empleó el análisis de contenido. El nivel de desarrollo curricular más analizado fue el currículo realizado, caracterizado por conocimientos aprendidos por los estudiantes. Ninguna investigación analizó el currículo evaluado. El tema más investigado fue el de disciplinas de los cursos y la mayoría de las investigaciones no utiliza referencias para conceptuar currículo. Se sugiere una mayor articulación entre los niveles del currículo con énfasis en el currículo evaluado.
'Secretaria Municipal de Educação e Esporte de Goiânia, Goiás. E-mail: msxufg@gmail.com

**Universidade Federal de Goiás (UFG). Goiânia, GO, Brasil. E-mail: arilazzarotti@gmail.com

Recebido em: 17-02-2019 Aprovado em: 29-05-2019 Publicado em: 03-11-2019

DOI: hitps://doi.org/10.22456/1982-8918.90369 (c) (1) (8) Licence 


\section{INTRODUÇÃO}

A formação em Educação Física no Brasil já foi objeto de interesse de vários pesquisadores do campo acadêmico e científico ${ }^{2}$ (BRITO NETO et al., 2000; CASTELLANI FILHO, 2016; RODRIGUES et al., 2016 entre outros). Embora muitos trabalhos já tenham sido publicados, congressos e eventos realizados, propostas e modelos discutidos, o tema formação ainda permanece atual.

Lazzarotti Filho, Silva e Mascarenhas (2014) afirmam que, no início dos anos 2000, a Educação Física começa a se consolidar enquanto um subcampo científico, estruturado a partir do aumento dos investimentos em ciência e tecnologia, do número de cursos de pósgraduação, periódicos científicos, bolsas e editais de fomento à pesquisa. Essa expansão reflete diretamente no aumento da quantidade de pesquisas publicadas e, consequentemente, na necessidade de avaliar a produção (VOSGERAU; ROMANOWSKI, 2014).

Maffei, Verardi e Pessôa Filho (2016) e Brito Neto et al. (2010), ao realizarem um levantamento das pesquisas veiculadas sobre formação de professores de Educação Física, identificaram pequena quantidade de artigos sobre o tema. Os autores concluíram que a maior parte das pesquisas concentrou-se na análise das alterações dos currículos dos cursos de Educação Física após mudanças na legislação.

Castellani Filho (2016) afirma que boa parte das pesquisas sobre formação em Educação Física ocupa-se de análises pontuais, não oferecendo um panorama da realidade dos cursos existentes no país. Além disso, 0 autor afirma que estas pesquisas têm se norteado mais por questões políticas e menos pelas teorias existentes sobre currículo, o que tornou 0 tema formação de professores (ou formação profissional) um "terreno minado" (CASTELLANI FILHO, 2016, p. 760).

Em se tratando do currículo, Sacristán (2000, p. 101) afirma que este é um fenômeno complexo e dinâmico, que "[...] não basta ficar na configuração estática que pode apresentar num dado momento, é necessário vê-lo na construção interna que ocorre em tal processo". Sacristán (2000) define seis níveis de desenvolvimento curricular, cada um com algum grau de autonomia, mas diretamente dependente dos demais. 0 primeiro nível é representado pela política curricular, o segundo pelo currículo apresentado aos professores, o terceiro pela modelação do currículo pelos professores, o quarto pelo currículo em ação, o quinto pelo currículo realizado e o sexto pelo currículo avaliado.

Assim, o currículo resulta de um processo no qual interagem diferentes agentes, motivados por diferentes interesses e teorias, muitas vezes contraditórias. Desta forma, tornase necessário compreender o percurso desenvolvido pelo currículo no sistema de ensino, esclarecendo os diferentes significados que ele assume em cada nível.

Esta pesquisa teve como objetivo investigar como as produções científicas veiculadas por periódicos no período de 2000 a 2017 têm analisado o currículo de formação em Educação Física. A seguir apresenta-se uma introdução às teorias do currículo, fundamentando-se em Silva (2005), seguida por um modelo de entendimento do currículo proposto por Sacristán (2000).

1 No decorrer do artigo será utilizado o termo formação para se referir à formação superior em Educação Física. 


\section{BASES TEÓRICAS}

\subsection{TEORIAS DO CURRÍCULO EM TOMAZ TADEU DA SILVA}

Silva (2005) afirma que o currículo surge como objeto de interesse e pesquisa primeiramente nos Estados Unidos nos anos 1920. Segundo o autor, a intensa industrialização, urbanização e migração vividas pelo país naquele período tornaram necessária a padronização da educação oferecida para a população. Assim, sustentada por uma visão técnica, racional e científica, a administração institui o currículo, na tentativa de prever e controlar os conhecimentos ensinados nas escolas.

As teorias tradicionais do currículo, como eram denominadas, concentravam-se na dimensão técnica e operacional em detrimento do próprio conteúdo do currículo. A partir de 1960, no entanto, com a efervescência dos movimentos políticos e sociais pelo mundo, surgem as "[...] teorizações que colocavam em xeque o pensamento e a estrutura educacional tradicionais" (SILVA, 2005, p. 29). Segundo Silva (2005, p. 30),

As teorias críticas desconfiam do status quo, responsabilizando-o pelas desigualdades e injustiças sociais. [...] As teorias críticas são teorias da desconfiança, questionamento e transformação radical. Para as teorias críticas o importante não é desenvolver técnicas de como fazer o currículo, mas desenvolver conceitos que nos permitam compreender o que o currículo faz (grifo do autor).

Alguns autores citados por Silva (2005) defensores de uma teoria crítica do currículo são Althusser, Michael Apple, Bourdieu e Passeron, Giroux, Paulo Freire e Saviani. Apple, por exemplo, se fundamenta no conceito de hegemonia de Antônio Gramsci para analisar o currículo escolar. Apple considera que as classes dominantes buscam constantemente manter sua hegemonia sobre as demais e, neste contexto, o currículo exerce papel essencial, pois reflete interesses desses grupos (SILVA, 2005).

Althusser, segundo Silva (2005), assevera que a função da escola e o currículo na sociedade capitalista é promover a adaptação dos indivíduos à vida nessa estrutura social, operando, dessa forma, como um aparelho ideológico do Estado. Ou seja, a escola e o currículo contribuem para a reprodução simbólica do modelo econômico e social vigente (SILVA, 2005).

De acordo com Silva (2005), Paulo Freire direciona sua crítica ao ensino tradicional, denominando-o de educação bancária. Nesse contexto, o professor deposita conhecimentos nos educandos e posteriormente os retira por meio das avaliações. A consequência desse ato mecânico é a completa desconsideração dos saberes, interesses e necessidades dos estudantes.

A partir de 1980, surgem em vários lugares do mundo novas teorias. Estas se caracterizavam por atribuir centralidade às relações de poder existentes na elaboração e desenvolvimento do currículo. Dentre essas novas teorias, denominadas por Silva (2005) de pós-críticas, situam-se o multiculturalismo, o feminismo, a teoria queer, o pós-modernismo, o pós-estruturalismo e o pós-colonialismo.

O multiculturalismo, por exemplo, surge como uma reivindicação de grupos culturais subordinados por mais espaço na escola e no currículo. Esses grupos criticavam o fato do currículo ser constituído por valores da cultura branca, masculina, europeia e heterossexual (SILVA, 2005). 
O pós-modernismo prioriza o hibridismo, a mistura de culturas, de estilos, etc. Privilegia análises locais e não universais, o subjetivismo ao objetivismo, a dúvida em detrimento da certeza. No âmbito da crítica ao currículo, o pós-modernismo o acusa de ser um objeto criado na modernidade, fundamentado nos princípios de racionalidade, linearidade e objetividade. Ao mesmo tempo, questiona a própria teoria crítica do currículo, por ter a pretensão de universalizar suas considerações sobre um fenômeno social (SILVA, 2005).

O pós-estruturalismo, por sua vez, entende que os significados são produzidos socialmente. Assim, questiona os diversos significados presentes no currículo, como pátria, ciência, religião, etc. Ao buscar elucidar as origens destes significados o pós-estruturalismo procura evidenciar os responsáveis pela sua elaboração e fixação no currículo (SILVA, 2005).

Feita esta aproximação às teorias do currículo, apresenta-se, a seguir, a compreensão do currículo proposta por Sacristán (2000).

\subsection{OS NIIVEIS DE DESENVOLVIMENTO DO CURRÍCULO EM JOSÉ GIMENO SACRISTÁN}

Sacristán (2000) define o currículo como uma construção social, resultado do embate de diferentes grupos, classes sociais e teorias. Nesse sentido, o currículo representa o "[...] equilíbrio de interesses e forças que gravitam sobre o sistema educativo num dado momento, enquanto através deles se realizam os fins da educação no ensino escolarizado" (SACRISTÁN, 2000, p. 17).

Nesta perspectiva, o currículo constitui-se como um fenômeno complexo, em constante movimento e sujeito à influência de múltiplos atores. Para entender esta complexidade, Sacristán (2000) estabelece seis níveis de desenvolvimento do currículo, os quais podem ser visualizados na figura abaixo ${ }^{3}$.

Figura 1 - A objetivação do currículo no processo de seu desenvolvimento.

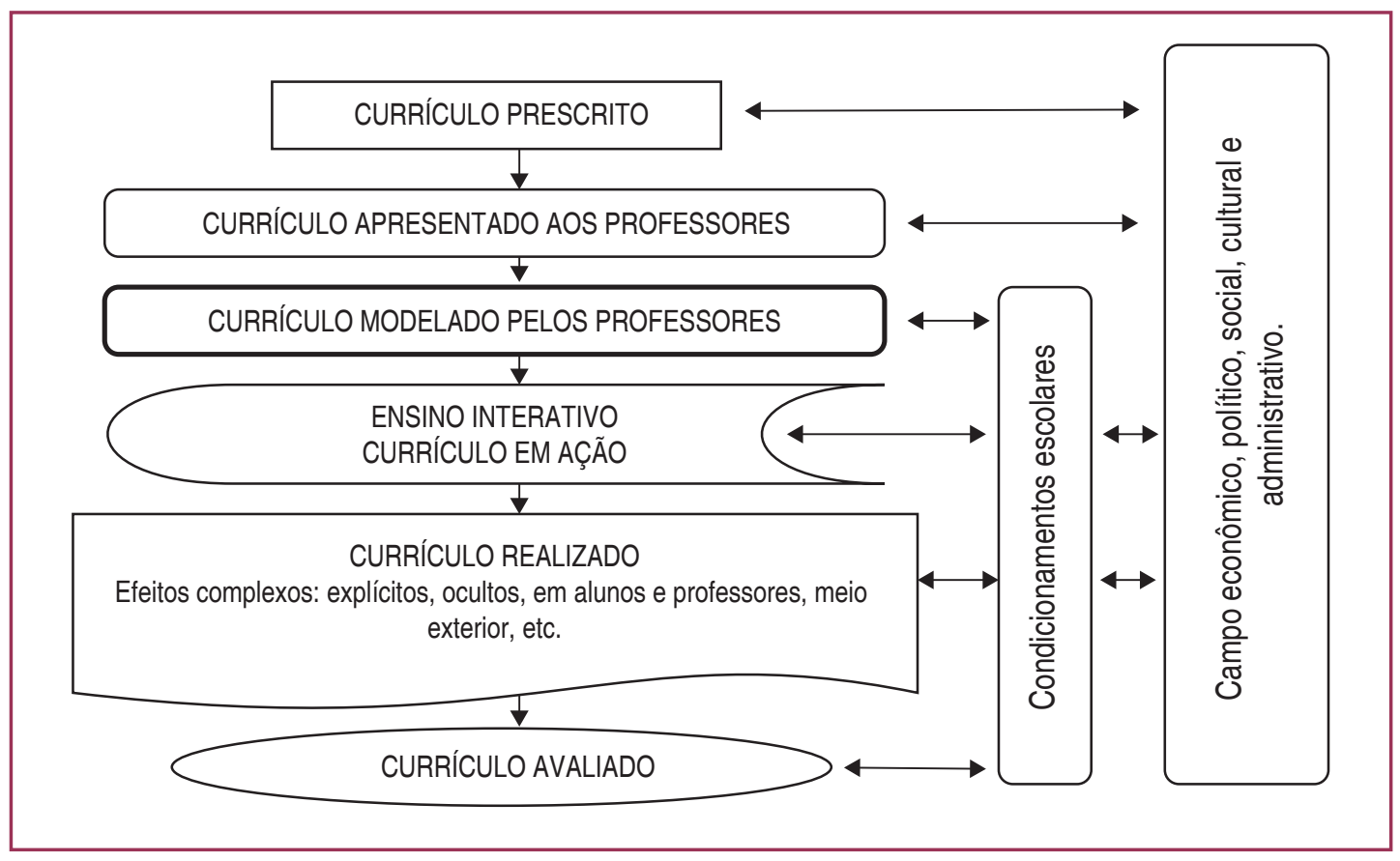

Fonte: Adaptado de Sacristán (2000, p. 105).

3 É importante destacar que este modelo explicativo do currículo foi elaborado com base em estudos que investigam o contexto escolar. Entretanto, ele também é empregado para analisar o currículo adotado ou elaborado por instituições de ensino superior (IES) responsáveis por oferecer cursos de formação profissional, como se observa nas pesquisas de Souza (2017), Nascimento (2017). 
Como se observa na figura acima, existe um campo econômico, político, social, cultural e administrativo que influencia o desenvolvimento do currículo, desde seu processo de elaboração até a sua avaliação. Esta relação é mais forte nos dois primeiros níveis do currículo (prescrito e apresentado aos professores), enquanto nos demais níveis esta interferência é filtrada pelos condicionamentos escolares, ou seja, pela estrutura de funcionamento da instituição educativa.

O primeiro nível do currículo constitui-se do currículo prescrito. Trata-se da política curricular responsável por estabelecer as decisões gerais e ordenar jurídica e administrativamente o currículo. A função básica do currículo prescrito é a definição de mínimos curriculares e a orientação do processo de ensino (SACRISTÁN, 2000).

A prescrição curricular é pouco operativa para os professores. Nesse sentido, existem documentos e materiais externos, como os livros didáticos, por exemplo, que servem de subsídio para a compreensão e desenvolvimento dos conteúdos previstos. Estes meios tradutores constituem o segundo nível de desenvolvimento do currículo, o currículo apresentado aos professores (SACRISTÁN, 2000).

Sacristán (2000, p. 175) afirma que "[... ] a implantação de qualquer currículo passa pelo crivo da interpretação dos profissionais de ensino". O professor, inserido em uma instituição de ensino, observa e interpreta a realidade a fim de tomar as decisões mais adequadas àquele contexto. A partir daí, ele define as parcelas e significados da cultura que poderão estimular aprendizagens e promover o desenvolvimento dos alunos. A modelação do currículo pelo professor constitui o terceiro nível de desenvolvimento curricular.

O currículo em ação, quarto nível de desenvolvimento curricular, refere-se às diversas situações de ensino onde os alunos interagem com as atividades propostas pelo professor. 0 entrecruzamento dos diferentes aspectos da aula (espaço, tempo, recursos materiais, estilo pedagógico, etc.) produzem efeitos educativos complexos e singulares.

O quinto nível de desenvolvimento curricular, o currículo realizado representa todas as aprendizagens adquiridas pelos estudantes no decorrer do processo de escolarização. Isso significa que "[...] toda a experiência que o aluno/a [sic] tem nos ambientes escolares" (SACRISTÁN, 1998, p. 132) agrega conhecimentos, habilidades e, também, comportamentos diversos, como formas de sentir, se adaptar, pensar, sobreviver, valorizar, etc.

O último nível de desenvolvimento do currículo é o currículo avaliado. A avaliação afere as aprendizagens obtidas pelos alunos, permitindo ao professor verificar a parcela apreendida do currículo. Assim, a análise das avaliações empregadas pelos professores permite identificar os conteúdos ou parcelas do currículo selecionadas e, portanto, privilegiadas no processo de ensino (SACRISTÁN, 2000).

Como se observou nesta breve síntese, cada nível de desenvolvimento do currículo tem uma determinada complexidade e interdependência em relação aos demais. Nessa perspectiva, devem ser analisados de forma conjunta a fim de se obter uma visão mais completa do fenômeno curricular.

\section{DECISÕES METODOLÓGICAS}

A pesquisa realizada foi do tipo bibliográfica. Marconi e Lakatos (2003, p. 183) afirmam que a pesquisa bibliográfica "[... não é mera repetição do que já foi dito ou escrito sobre certo 
assunto, mas propicia o exame de um tema sob novo enfoque ou abordagem, chegando a conclusões inovadoras". As pesquisas bibliográficas, segundo Vosgerau e Romanowski (2014, p. 167), "[...] permitem a compreensão do movimento da área, sua configuração, propensões teóricas metodológicas, análise crítica indicando tendências, recorrências e lacunas".

O recorte da pesquisa foi quanti-qualitativo fundamentado na técnica de análise de conteúdo. Para Amado (2013, p. 300), a análise de conteúdo consiste em uma técnica capaz de "[...] fazer inferências interpretativas a partir de conteúdos expressos", buscando a compreensão destes. A análise de conteúdo, segundo Amado (2013), é composta por seis fases. São elas: definição do problema e dos objetivos do estudo, explicitação de um quadro de referência teórico, constituição de um corpus documental, leitura atenta e ativa, formulação de hipóteses e categorização.

O processo de constituição do corpus documental da pesquisa seguiu cinco etapas:

1a Identificação dos periódicos científicos avaliados pelo Qualis periódicos da Coordenação de Aperfeiçoamento de Pessoal de Nível Superior (Capes) nos extratos de A1 até B3 em Educação Física no quadriênio 2013-2016.

2a Aplicação de critérios de inclusão a fim de manter na pesquisa somente aqueles periódicos que publicassem artigos relacionados ao tema da formação em Educação Física. Os critérios foram: serem nacionais, terem periodicidade em dia, possuírem artigos na íntegra disponíveis online e foco e escopo relacionados às subáreas social, cultural e pedagógica da Educação Física. Após a aplicação desses critérios, foram mantidos dez periódicos.

$3^{\text {a }}$ Nos sites das dez revistas selecionadas, foi realizada a busca de artigos com as palavraschave: "formação de professores"; "formação profissional", "formação inicial", "formação continuada" e "currículo", no título ou no resumo do trabalho. Nesta busca inicial foram recuperados 554 artigos.

4- Adoção de critérios de exclusão de artigos não relacionados ao tema da pesquisa. Os critérios foram: artigos que analisavam currículo escolar ou o currículo Lattes, artigos publicados fora do recorte temporal estabelecido, artigos indisponíveis, artigos que não continham os termos da pesquisa, artigos em que formação aparece apenas como um resultado ou como recorte da pesquisa, artigos que analisavam a formação em outras áreas ou cursos e artigos que investigavam a formação em outros países. Assim, foram mantidos 346 artigos.

$5^{\text {a }}$ Restrição do tipo de trabalho a fim de incluir somente artigos originais que apresentassem resultados de pesquisa empírica, uma vez que a perspectiva era identificar os níveis de desenvolvimento do currículo como resultado de pesquisas. Dentre os artigos excluídos nessa etapa encontram-se ensaios, artigos de revisão, relatos de experiência, pontos de vista, editoriais, entrevista, resenhas e resumos. Após a etapa, chegou-se aos artigos analisados, 230.

A pesquisa foi realizada nos meses de maio e junho de 2018. A lista dos periódicos científicos e a quantidade total de artigos originais sobre formação em Educação Física identificados em cada um deles pode ser observada no Quadro 1. 
Quadro 1 - Quantidade de artigos publicados em cada periódico sobre formação em Educação Física durante o período analisado (2000-2017).

\begin{tabular}{|l|c|}
\hline PERIÓDICO & ARTIGOS ORIGINAIS \\
\hline Movimento & 43 \\
\hline Revista Brasileira de Ciências do Esporte (RBCE) & 41 \\
\hline Pensar a Prática & 41 \\
\hline Motrivivência & 40 \\
\hline Motriz & 17 \\
\hline Revista Brasileira de Educação Física e Esporte (RBEFE) & 15 \\
\hline Journal of Physical Education (Revista da UEM) & 15 \\
\hline Revista Brasileira de Ciência e Movimento (RBCM) & 8 \\
\hline Licere & 7 \\
\hline Revista Brasileira de Atividade Física e Saúde (RBAFS) & 3 \\
\hline TOTAL & $\mathbf{2 3 0}$ \\
\hline
\end{tabular}

Fonte: Dados da pesquisa.

Após a constituição do corpus documental foi realizada uma leitura atenta e ativa dos artigos (títulos, resumos e palavras-chave). A categorização dos dados, sexta e última fase da análise de conteúdo, seguiu o procedimento misto. As categorias a priori foram definidas com base nos níveis de desenvolvimento do currículo propostos por Sacristán (2000). Os indicadores dessas categorias podem ser observados abaixo:

- Currículo prescrito: Diretrizes Curriculares, Resoluções, Pareceres, etc.

- Currículo apresentado aos professores: Projetos Pedagógicos de Curso (PPCs ${ }^{4}$ ), matrizes curriculares, ementas de disciplinas, etc.

- Currículo modelado pelos professores: planos de ensino, concepções e teorias que fundamentam o trabalho dos professores dos cursos.

- Currículo em ação: aulas, experiências de ensino, projetos, etc.

- Currículo realizado: conhecimentos, habilidades, comportamentos, etc. adquiridos pelos estudantes.

- Currículo avaliado: instrumentos utilizados para avaliar disciplinas, currículos, cursos, etc.

É importante destacar que durante a leitura dos dados também foi necessária a criação de uma categoria a posteriori para a análise dos níveis de desenvolvimento curricular denominada múltiplos níveis, que retratava aquelas pesquisas que analisavam mais de um nível de desenvolvimento do currículo. A construção e a definição de categorias para representar os temas dos artigos também foram realizadas após a leitura dos trabalhos.

Em relação à identificação das obras e autores referência sobre currículo, foi realizado um procedimento diferente. Cada artigo era aberto na íntegra no navegador Google Chrome e, em seguida, era utilizada a ferramenta "localizar" e digitado o termo "curr"." A partir daí observava-se se o termo era acompanhado por algum autor. Em caso afirmativo, pesquisavase, nas referências do artigo, o nome completo do autor e o título da obra. Para facilitar o trabalho

4 Embora os PPCs das instituições sejam elaborados pelos próprios professores, entende-se que ele orienta e define as interpretações possíveis do currículo.

5 A utilização do radical da palavra permitiu identificar não apenas o termo currículo como também palavras derivadas como curricular. 
de organização, tabulação e categorização dos dados foi o utilizado o software Excel. Após a codificação, procedia-se com a contabilização da frequência com que os dados apareciam.

\section{ANÁLISE E DISCUSSÃO DOS DADOS}

Apresenta-se, a seguir, uma caracterização geral da produção científica veiculada sobre a formação em Educação Física. Logo após, são exibidos e discutidos os dados sobre os níveis do currículo, temas das pesquisas e autores e obras utilizadas como referência para a compreensão do currículo.

A Figura 2 apresenta a quantidade total de artigos publicados comparada com a quantidade de artigos publicados sobre o tema formação em Educação Física pelas revistas ao longo do período analisado.

Figura 2 - Quantidade total de artigos publicados comparada com a quantidade de artigos publicados sobre 0 tema formação em Educação Física pelas revistas ao longo do período analisado.

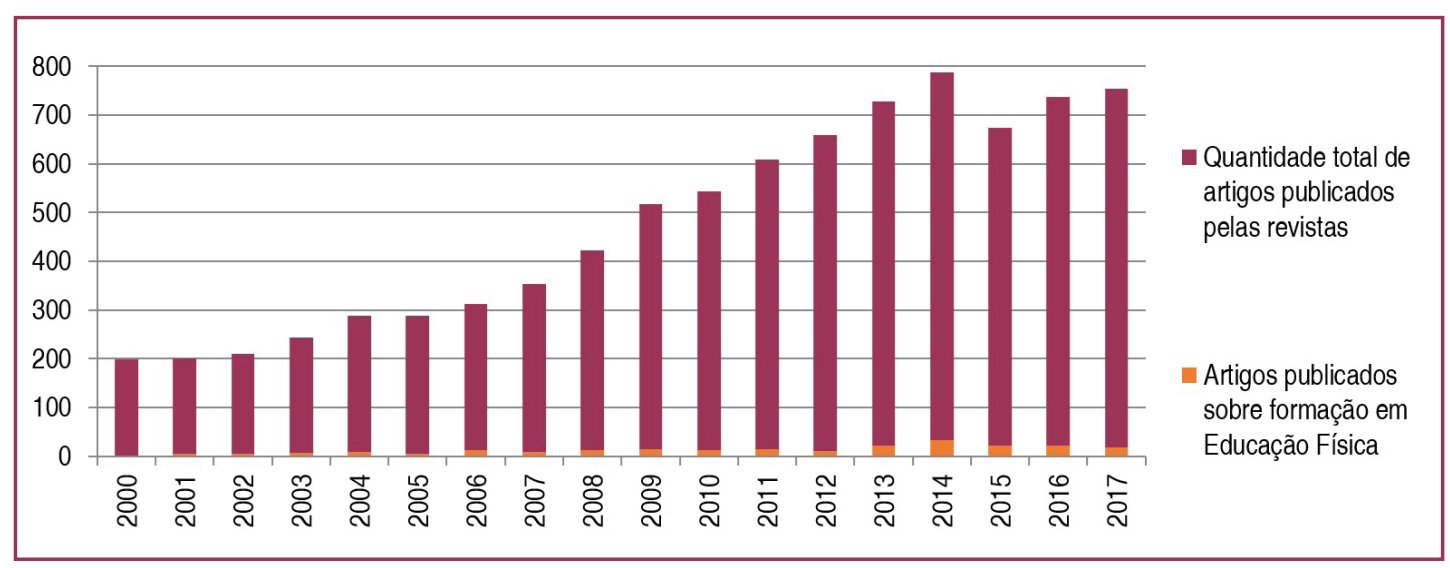

Fonte: Dados da pesquisa.

A Figura 2 demonstra que a quantidade total de artigos publicados pelas revistas de 2000 a 2017 aumentou consideravelmente. Por outro lado, a mesma figura também indica que a publicação de artigos sobre o tema formação em Educação Física é praticamente incipiente, alcançando números pouco expressivos no contexto da publicação de artigos em geral. De um total de 8.304 artigos publicados entre 2000 e 2017, somente 230 correspondiam a pesquisas sobre formação em Educação Física, perfazendo 2,8\% do total.

Brito Neto et al. (2010), ao realizarem um levantamento dos artigos publicados sobre formação de professores em 12 periódicos ${ }^{6}$, identificaram um resultado ligeiramente superior. De um total de 2.220 artigos publicados, 182 trabalhos eram sobre o tema investigado, 0 equivalente a $8 \%$ do total.

Essa diferença entre a proporção de artigos identificados por Brito Neto (2010) e aqueles encontrados na pesquisa pode ser parcialmente explicada pelo fato de terem sido excluídos deste trabalho os ensaios, resumos, resenhas, editoriais, pontos de vista, entrevistas, relatos de experiência, artigos de revisão, pesquisas que indicam a formação como recorte ou como resultado e pesquisas que analisam a formação em outros cursos, áreas ou países.

6 Dos periódicos utilizados como fonte de dados por Brito Neto et al. (2010), sete integraram a presente pesquisa. São eles: Motrivivência, Motriz, Movimento, Pensar a Prática, Revista Brasileira de Ciências do Esporte (RBCE), Revista Brasileira de Educação Física e Esporte (RBEFE) e Revista da Educação Física (UEM). 
Apesar disso, é possível considerar pelos dados apresentados que 0 aumento na quantidade de pesquisas publicadas sobre formação em Educação Física não tem acompanhado o crescimento progressivo experimentado pelo subcampo acadêmico-científico da área, tal como descrito anteriormente por Lazzarotti Filho, Silva e Mascarenhas (2014).

Na Figura 3 é apresentada especificamente a quantidade total de artigos publicados sobre formação em Educação Física em cada ano do período analisado (2000-2017).

Figura 3 - Quantidade total de artigos publicados sobre formação em Educação Física em cada ano do período analisado (2000-2017).

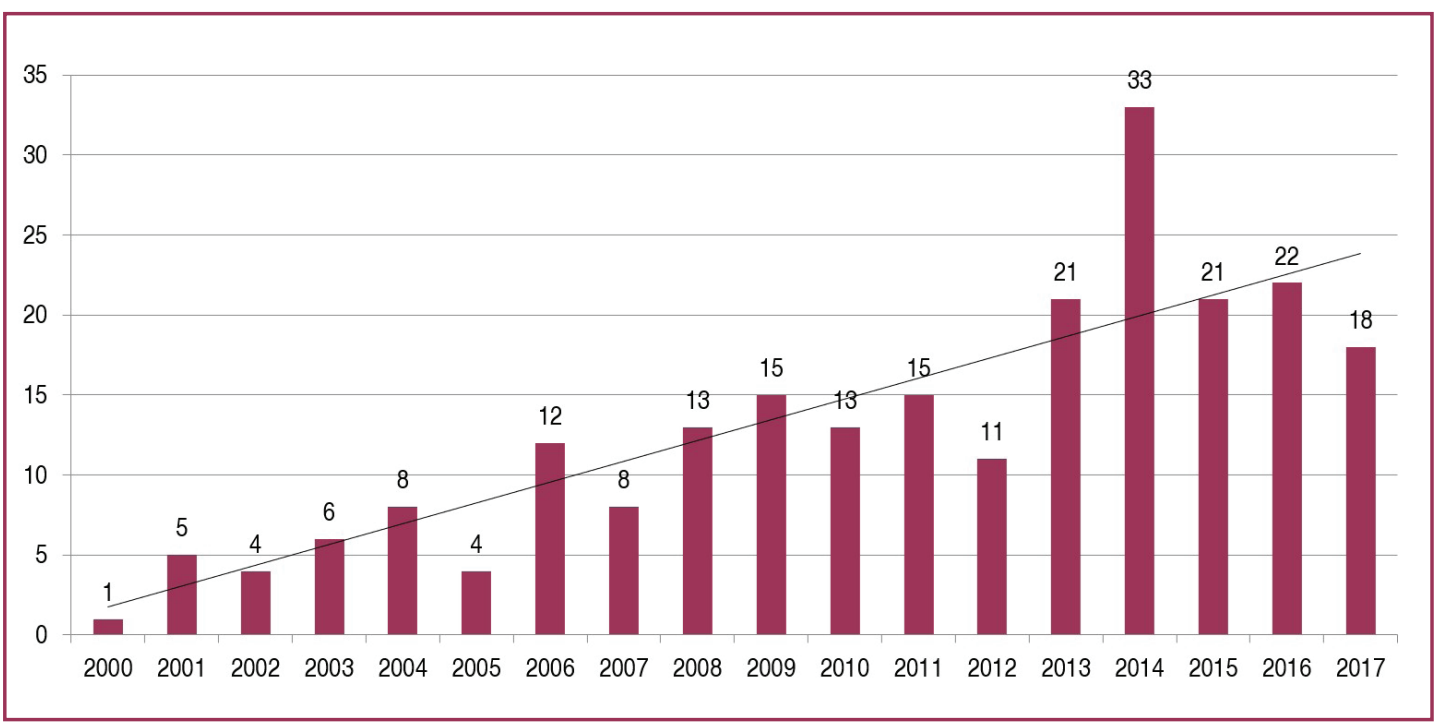

Fonte: Dados da pesquisa

A figura acima nos permite visualizar que há um crescimento lento e irregular de artigos publicados sobre o tema da formação, oscilando em determinados anos e apresentando um pico em 2014. Esse pico pode estar relacionado com a publicação, pela RBCE, de um volume extra com 60 artigos apresentados no XVIII Congresso Brasileiro de Ciências do Esporte (CONBRACE) de 2013. Dentre os seis artigos publicados do Grupo de Trabalho Temático (GTT) Formação Profissional e Mundo do Trabalho encontram-se trabalhos que versam sobre Diretrizes Curriculares Nacionais, megaeventos esportivos e avanço neoliberal e suas consequências para a formação profissional em Educação Física.

Além disso, no mesmo ano a revista Motrivivência publica uma seção temática com nove artigos para discutir os dez anos de aprovação das Diretrizes Curriculares para a formação de professores, realizando um balanço da adequação dos currículos dos cursos de formação em Educação Física, bem como analisando limites e possibilidades das novas diretrizes.

Isso demonstra que a veiculação sobre o tema formação acontece, de forma mais expressiva, quando impulsionada por determinadas demandas, não se mantendo, assim, no decorrer do tempo. Algo semelhante também foi constatado por Brito Neto et al. (2010), que associaram 0 aumento na quantidade de artigos sobre formação com a aprovação das DCNs para a formação de professores de Educação Física no ano de 2004. Segundo os autores,

No início da primeira década de 2000 , as produções sobre o campo se tornaram mais regulares e contínuas e que, em meados desta mesma década, houve um significativo crescimento que atribuímos ao efervescente embate em torno das 
Diretrizes Curriculares Nacionais para a Formação de Professores de Educação Física (BRITO NETO et al., 2010, p. 69).

Na Figura 4 é apresentada a quantidade de artigos categorizada em cada um dos níveis de desenvolvimento curricular.

Figura 4 - Quantidade de artigos categorizada em cada um dos níveis de desenvolvimento do currículo proposto por Sacristán (2000).

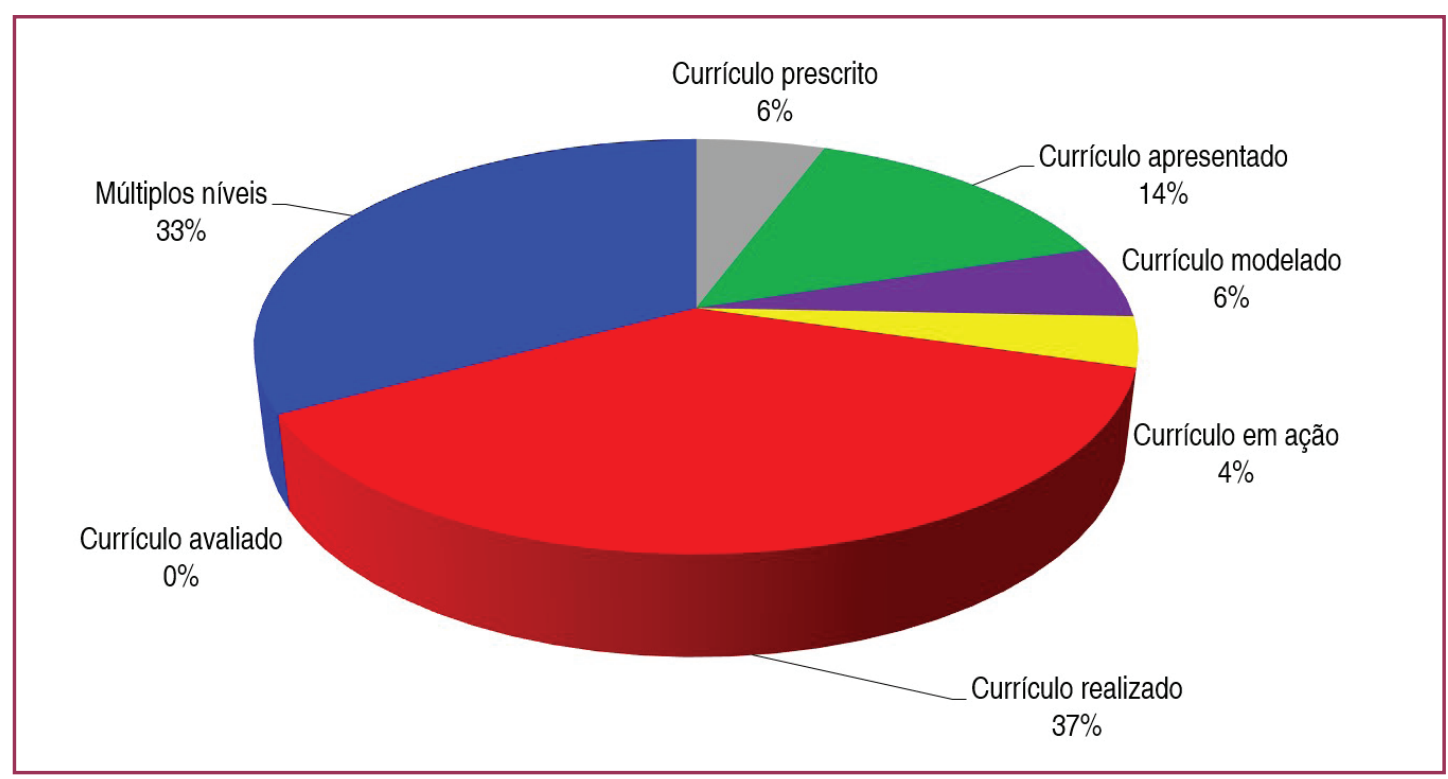

Fonte: Dados da pesquisa.

Como se observa na Figura 4, o nível do currículo analisado por um maior número de pesquisas foi o currículo realizado com $37,4 \%$ do total. Esse nível compreende todos os efeitos previstos ou não do ensino, tanto sobre estudantes como sobre os professores. As pesquisas desse conjunto, em sua maior parte, analisaram se os conhecimentos adquiridos na formação (inicial ou continuada) foram suficientes para a atuação profissional.

A categoria múltiplos níveis aparece em segundo lugar com maior quantidade de artigos, $33 \%$ do total. Nesse conjunto, foram situadas pesquisas que analisaram mais de um nível de desenvolvimento do currículo. A maior parte dessas pesquisas (55\%) analisou relações entre dois níveis do currículo. Nesse conjunto, se destacaram pesquisas que investigaram relações entre o currículo prescrito e o currículo apresentado aos professores.

Nenhuma pesquisa analisou os seis níveis de desenvolvimento do currículo. Assim, observa-se que a maior parte das pesquisas concentrou-se em aspectos parciais do currículo e da formação, tal como identificado nos trabalhos de Maffei, Verardi, Pessôa Filho (2016) e de Brito Neto et al. (2010).

O currículo apresentado aos professores foi identificado em 14,3\% do total de artigos constituindo assim o terceiro nível com maior número de pesquisas. Este nível é representado por pesquisas que analisaram Projetos Pedagógicos de Curso (PPCs), matrizes curriculares, ementas de disciplinas, entre outros documentos oficiais que constituem o currículo elaborado pelas IES e que são apresentados formalmente aos professores.

O currículo prescrito e o currículo modelado pelos professores ocuparam o quarto nível com maior número de artigos, sendo observados em 13 artigos cada. Nesta pesquisa o currículo 
prescrito é representado por Resoluções, Diretrizes Curriculares entre outras legislações que orientam e regulam a formação superior em Educação Física. 0 currículo modelado pelos professores, por sua vez, é observado nas perspectivas e metodologias de ensino adotadas pelos professores no desenvolvimento do currículo.

O currículo em ação foi analisado por nove pesquisas. Este nível de desenvolvimento do currículo se refere ao ensino interativo, ou seja, às experiências formativas, como aulas, projetos de extensão, pesquisa, eventos realizados, etc. Neste conjunto, encontraram-se pesquisas que analisaram cursos de formação continuada, experiências de ensino no estágio e incursão de estudantes do Programa Institucional de Bolsa de Iniciação à Docência (PIBID) nas escolas.

O currículo avaliado não foi constatado em nenhuma pesquisa sobre formação em Educação Física. Apenas quatro artigos foram identificados na categoria múltiplos níveis que analisaram o currículo avaliado na relação com outros níveis do currículo. Isso indica que as avaliações empregadas nas disciplinas e nos cursos (como 0 Enade ${ }^{7}$ ) não têm recebido a atenção dos pesquisadores, o que limita a compreensão dos conhecimentos privilegiados no ensino, bem como da influência que a avaliação exerce sobre a constituição do próprio currículo (SACRISTÁN, 2000).

$\mathrm{Na}$ figura abaixo é possível observar os temas identificados nas pesquisas sobre formação em Educação Física e a proporção de artigos veiculados sobre cada tema. É importante ressaltar que estes temas são categorias a posteriori, isto é, surgiram durante 0 processo de leitura e análise dos dados.

Figura 5 - Temas das pesquisas e proporção de artigos veiculados sobre cada tema.

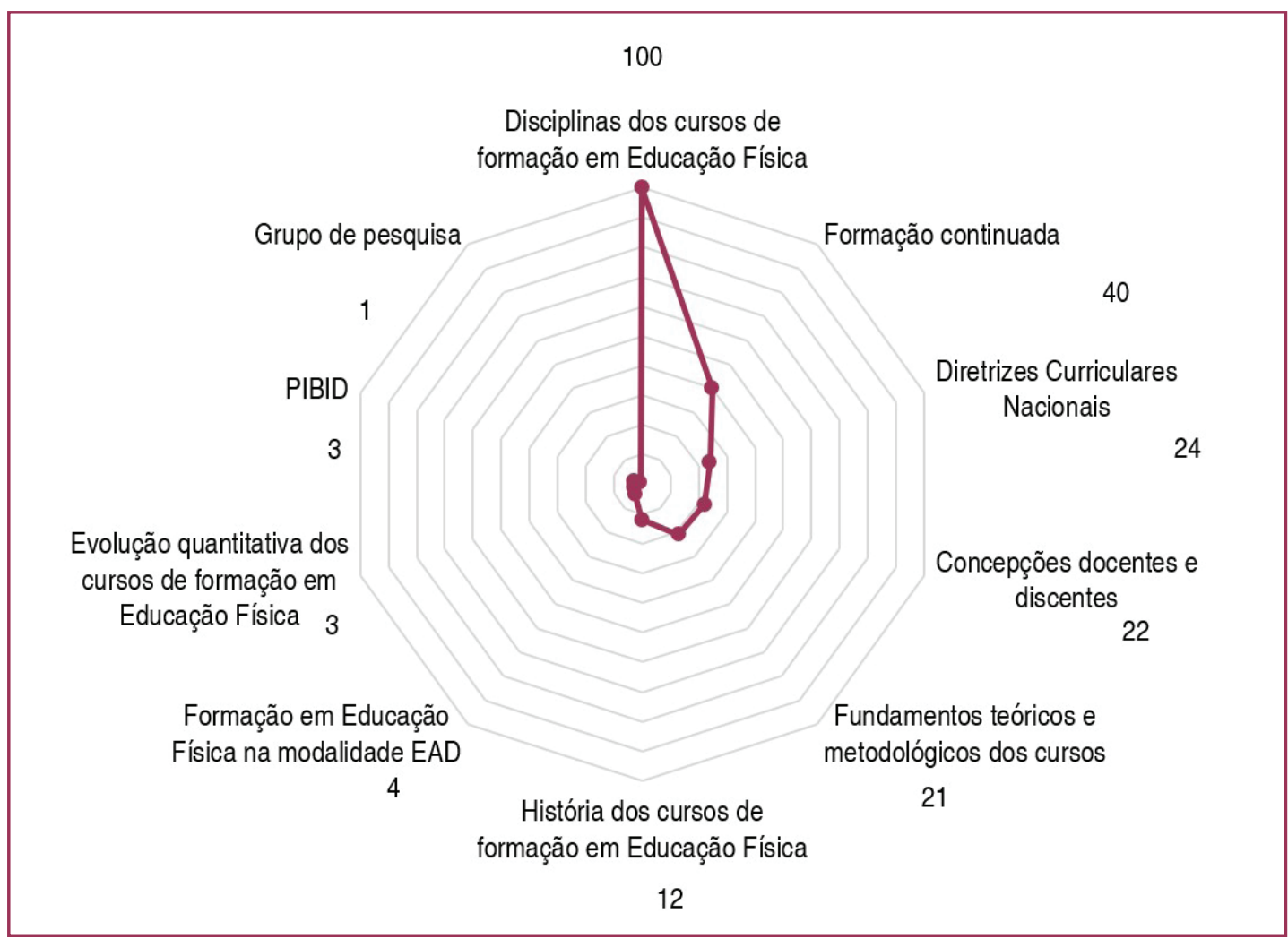

Fonte: Dados da pesquisa.

7 "O Exame Nacional de Desempenho de Estudantes (Enade) avalia o rendimento dos concluintes dos cursos de graduação, em relação aos conteúdos programáticos, habilidades e competências adquiridas em sua formação". Disponível em: http://portal.inep.gov.br/enade. Acessado em: 19 out. 2018. 
A figura acima indica que o tema mais recorrente entre as pesquisas foi "Disciplinas dos cursos de formação em Educação Física", com 100 artigos. O segundo tema mais frequente foi "Formação continuada", com 40. Em terceiro lugar aparece o tema "Diretrizes Curriculares Nacionais", com 24 artigos, e em quarto "Concepções docentes e discentes", com 22 artigos, seguido por "Fundamentos teóricos e metodológicos dos cursos", com 21 artigos. Isso demonstra que há grande preocupação dos pesquisadores em analisar a constituição e 0 andamento dos cursos de formação em Educação Física.

Outros cinco temas identificados em menor quantidade de artigos foram "História dos cursos de formação em Educação Física" (12), "Formação em Educação Física na modalidade EAD" (4), "Evolução quantitativa dos cursos de formação em Educação Física", "PIBID" (3) e "Grupo de pesquisa" (1). Tais temas indicam que análises históricas dos cursos são ainda incipientes, algo semelhante ao que acontece em relação à análise dos cursos em EAD, ao aumento ou redução da quantidade cursos, ao PIBID e ao funcionamento de grupos de pesquisa.

Os temas encontrados na pesquisa se assemelham àqueles encontrados por Brito Neto et al. (2010). Os autores, ao analisarem os artigos veiculados sobre formação de professores Educação Física constataram que o tema mais recorrente foi "currículo e disciplinas", seguido por "atuação profissional" e "concepções e princípios orientadores" (BRITO NETO et al., 2010, p. 65). Isso evidencia que os temas não têm se modificado de forma significativa nos últimos anos.

No quadro abaixo são apresentados os autores utilizados pelas pesquisas veiculadas sobre formação em Educação Física para conceituar e discutir currículo. Pela grande quantidade de autores, optou-se por apresentar somente aqueles que foram citados em três ou mais artigos.

Quadro 2 - Autores(as) referência sobre currículo utilizadas pelas pesquisas e quantidade de artigos em que foram citados.

\begin{tabular}{|l|c|}
\hline AUTORES(AS) & QUANTIDADE DE ARTIGOS EM QUE FORAM CITADOS(AS) \\
\hline Tomas da Silva & 15 \\
\hline José Sacristán & 14 \\
\hline Antônio Moreira & 8 \\
\hline João Paraskeva & 4 \\
\hline José Pacheco & 3 \\
\hline Basil Bernstein & 3 \\
\hline Alfredo Veiga Neto & 3 \\
\hline Nenhum autor/a & 186 \\
\hline
\end{tabular}

Fonte: Dados da pesquisa.

Como é possível observar no quadro acima, 186 artigos não utilizaram nenhum autor ou obra como referência teórica para conceituar ou discutir currículo, o que corresponde a $81 \%$ das pesquisas veiculadas sobre formação em Educação Física. Esse resultado corrobora aqueles identificados por Brito Neto et al. (2010) ao constatarem a ausência de fundamentação teórica nas análises sobre formação. 
Castellani Filho (2016), na mesma direção, afirma que as pesquisas que analisam a alteração dos currículos pelas instituições de ensino após a implementação das Diretrizes Curriculares Nacionais têm se sustentado mais em posicionamentos políticos do que nas teorias existentes sobre o currículo.

Não se pretende aqui, no entanto, afirmar que os estudos sobre currículo devam ser obrigatoriamente tratados nas pesquisas sobre formação profissional em Educação Física. Busca-se somente destacar que a ausência deste campo teórico prejudica e limita as análises e debates sobre o tema da formação.

Em relação aos autores citados como referência sobre currículo nas pesquisas, observou-se preponderância de Tomaz da Silva e José Sacristán, citados em 15 e 14 trabalhos, respectivamente. A partir da análise da obra do próprio Tomaz da Silva (2005), é possível identificar esses autores como pertencentes ao conjunto das teorias pós-críticas do currículo.

Por outro lado, a pouca presença de autores como Bernstein, citado em três artigos, Giroux e Apple, identificados em apenas dois trabalhos cada um, indica baixa apropriação e uso das teorias críticas pelo subcampo científico da Educação Física no âmbito das pesquisas sobre formação.

A maior recorrência de autores vinculados à teoria pós-crítica do currículo também foi observada nas obras utilizadas pelos artigos como referência sobre currículo, como se pode observar no quadro abaixo. Assim como no quadro anterior, optou-se por apresentar somente as obras citadas em três ou mais artigos.

Quadro 3 - Obras mais referenciadas sobre currículo nas pesquisas veiculadas sobre formação em Educação Física.

\begin{tabular}{|l|c|}
\hline OBRAS & ARTIGOS \\
\hline SACRISTÁN, J. G. O currículo: uma reflexão sobre a prática. & 11 \\
\hline SILVA, T. T. Documentos de Identidade: uma introdução às teorias do currículo. & 5 \\
\hline MOREIRA, A. F. B.; SILVA. T. T. Currículo, cultura e sociedade. & 4 \\
\hline PARASKEVA, J. M. Educação e Poder. Abordagem críticas e pós-estruturais. & 4 \\
\hline PACHECO, J. A. Escritos curriculares. & 3 \\
\hline SILVA, T. T. O currículo como fetiche: a poética e a política do texto curricular. & 3 \\
\hline
\end{tabular}

Fonte: Dados da pesquisa.

Observa-se no quadro acima que a obra de Sacristán foi a mais recorrente entre os artigos na análise do currículo. Além desta, há grande uso de obras de Tomaz da Silva. Pelo título das obras é possível entrever uma maior aproximação das pesquisas sobre formação em Educação Física com teorias pós-críticas do currículo, tais como multiculturalismo, pósestruturalismo e pós-modernismo, devido à relação com o discurso e o texto.

Ao mesmo tempo, o predomínio de análises das disciplinas revela o ensejo dos pesquisadores em compreender questões locais e específicas dos cursos, sobretudo a partir da visão dos estudantes e egressos, considerando a representatividade do currículo realizado no âmbito das pesquisas sobre formação em Educação Física. 


\section{CONCLUSÃO}

A pesquisa demonstrou que a quantidade de artigos publicados sobre o tema formação em Educação Física foi baixa comparada à proporção total de trabalhos veiculados pelo subcampo científico da Educação Física no período de 2000 a 2017. Além disso, a veiculação sobre o tema nos pareceu ser impulsionada por acontecimentos específicos, não se apresentando de forma consolidada na agenda de pesquisa da comunidade científica.

Observou-se que o currículo realizado foi o nível de desenvolvimento curricular mais investigado, enquanto o currículo avaliado não foi identificado de forma isolada em nenhuma pesquisa. O tema mais recorrente foi "Disciplinas dos cursos de formação" e quase todos os trabalhos publicados não utiliza autores para conceituar currículo.

De um modo geral, a pesquisa permitiu identificar que a maior quantidade de artigos publicados sobre a formação constitui-se de trabalhos que buscaram investigar os significados das disciplinas dos cursos de formação em Educação Física para os estudantes e profissionais formados. Desta maneira, os resultados corroboram trabalhos anteriores de que as pesquisas estariam, em sua maior parte, circunscritas a análises parciais do currículo e da formação.

A maior quantidade de análises sobre casos particulares do ensino e da formação em Educação Física pode ser explicada, em alguma medida, pela preponderância das teorias pós-críticas nas pesquisas, preocupadas com questões subjetivas e locais, diferentemente da teoria crítica, que se orienta mais pela racionalidade e pela tentativa de compreensão das influências macrossociais e econômicas sobre o currículo.

Observa-se a necessidade de realizar pesquisas que investiguem os diversos níveis de desenvolvimento do currículo, com ênfase no currículo avaliado, nível praticamente ausente nos trabalhos analisados. Também há necessidade de pesquisas que comparem o tema formação com os demais temas publicados no campo da Educação Física. Os vários desafios existentes no âmbito da formação profissional em Educação Física exigem pesquisas fundamentadas teoricamente e com múltiplos olhares capazes de compreender a complexidade da realidade existente.

\section{REFERÊNCIAS}

AMADO, João. Manual de investigação qualitativa em educação. Coimbra: Imprensa da Universidade de Coimbra, 2013.

BRITO NETO, Anibal Correia Brito et al. O estágio de desenvolvimento do campo de estudo em "Formação de professores de Educação Física": primeiras aproximações. In: TERRA, Dinah Vasconcellos; SOUZA JÚNIOR, Marcílio (orgs.) Formação em Educação Física e Ciências do Esporte: políticas e cotidiano. São Paulo: Aderaldo \& Rothschild: Goiânia: CBCE, 2010. p. 49-74.

CASTELLANI FILHO, Lino. A formação sitiada. Diretrizes Curriculares de Educação Física em disputa: jogo jogado? Pensar a Prática, v. 19, n. 4, out./dez. 2016. Disponível em: https://www. revistas.ufg.br/fef/article/view/42256/pdf. Acesso em: 19 out. 2018. 
LAZZAROTTI FILHO, Ari; SILVA, Ana Márcia; MASCARENHAS, Fernando. Transformações contemporâneas do campo acadêmico-científico da Educação Física no Brasil: novos habitus, modus operandi e objetos de disputa. Movimento, v. 20, n. esp., p. 67-80, 2014. Disponível em: https://seer.ufrgs.br/Movimento/article/view/48280/32814. Acesso em: 19 out. 2018.

MAFFEI, Willer Soares; VERARDI, Carlos Eduardo Lopes; PESSÔA FILHO, Dalton Müller. Formação inicial do professor de Educação Física: produções acadêmicas entre 2005 - 2014. Motrivivência v. 28, n. 49, p. 146-163, 2016. Disponível em: https://periodicos.ufsc.br/index.php/ motrivivencia/article/view/2175-8042.2016v28n49p146/32961. Acesso em: 19 out.2018.

MARCONI, Marina de Andrade; LAKATOS, Eva Maria. Fundamentos de Metodologia Científica. 5. ed. São Paulo: Atlas, 2003.

NASCIMENTO, Oromar Augusto dos Santos. Os conhecimentos do lazer nos Projetos Pedagógicos de Cursos presenciais de Licenciatura em Educação Física no Estado de Goiás. Dissertação (Mestrado em Educação Física) - Faculdade de Educação Física, Universidade de Brasília, Brasília, 2017.

RODRIGUES, Anegleyce Teodoro et al. Análise da Minuta de Projeto de Resolução de Diretrizes Curriculares Nacionais para o curso de Educação Física e a questão da formação para a docência na educação básica. Pensar a Prática, v. 19, n. 4, out./dez. 2016. Disponível em: https://www.revistas.ufg.br/fef/article/view/42160. Acesso em: 19 out. 2018.

SACRISTÁN, José Gimeno. O currículo: os conteúdos do ensino ou uma análise prática? In: SACRISTÁN, José Gimeno; PÉREZ GÓMEZ, Ángel I. Compreender e transformar o ensino. Porto Alegre, Artmed, 1998. p. 119-148.

SACRISTÁN, José Gimeno. 0 currículo: uma reflexão sobre a prática. Porto Alegre: Artmed, 2000.

SILVA, Tomaz Tadeu da. Documentos de identidade: uma introdução às teorias do currículo. Belo Horizonte: Autêntica, 2005.

SOUZA, Bárbara Isabela de. Currículo e formação de professores: análise dos projetos pedagógicos dos cursos de Educação Física em Goiás. Dissertação (Mestrado em Educação Física) - Faculdade de Educação Física, Universidade de Brasília, Brasília, 2017. Disponível em: http://repositorio.unb.br/bitstream/10482/25324/1/2017 B\%c3\%a1rbaralsabelaSoaresdeSouza.pdf. Acesso em: 19 out. 2018.

VOSGERAU, Dilmeire Sant'anna Ramos; ROMANOWSKI, Joana Paulin. Estudos de revisão: implicações conceituais e metodológicas. Revista Diálogo Educacional, v. 14, n. 41, jan./ abr. 2014. Disponível em: https://periodicos.pucpr.br/index.php/dialogoeducacional/article/ view/2317/2233. Acesso em: 19 out. 2018.

Apoio:

O presente trabalho foi realizado com apoio da Coordenação de Aperfeiçoamento de Pessoal de Nível Superior - Brasil (CAPES) - Código de Financiamento 001. 